\title{
Soy intake and breast cancer risk in Singapore Chinese Health Study
}

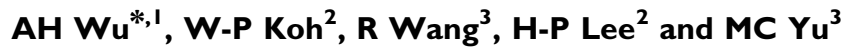 \\ 'Department of Preventive Medicine; University of Southern California Keck School of Medicine, Los Angeles, CA 90089, USA; ${ }^{2}$ Department of \\ Community, Occupational and Family Medicine, Yong Loo Lin School of Medicine, National University of Singapore, Singapore; ${ }^{3}$ The Cancer Center, \\ University of Minnesota, Minneapolis, MN 55455, USA
}

We investigated the effects of soy isoflavone intake on breast cancer in a prospective study of 35303 Singapore Chinese women enrolled during April 1993 to December 1998 in the Singapore Chinese Health Study. At recruitment, each subject was personally administered a validated semiquantitative food frequency questionnaire covering 165 food and beverage items. As of December 3 I 2005, 629 had developed breast cancer following an accumulation of 338242 person-years. Using Cox regression and adjusting for age at interview, year of interview, dialect group, education, family history of breast cancer, age when periods became regular, parity, menopausal status, body mass index (BMI), n-3 fatty acid, and other covariates, we found breast cancer risk was reduced significantly in association with high soy intake. Relative to women with lower (below median) soy intake $(<10.6 \mathrm{mg}$ isoflavone per I000 Kcal), women with higher (above median) intake showed a significant I $8 \%$ risk reduction (relative risk $(R R)=0.82,95 \%$ confidence interval $(\mathrm{Cl})=0.70-0.97)$. This inverse association was apparent mainly in postmenopausal women $(\mathrm{RR}=0.74,95 \% \mathrm{Cl}=0.6 \mathrm{I}-0.90)$, and was not observed in premenopausal women $(R R=1.04,95 \% \mathrm{Cl}=0.77-1.40)$. Among postmenopausal women, the soy-breast cancer association was stronger in those above median $\mathrm{BMI}(\mathrm{RR}=0.67,95 \% \mathrm{Cl}=0.5 \mathrm{I}-0.88)$ than in leaner women $(R R=0.83,95 \%$ $\mathrm{Cl}=0.62-\mathrm{I} . \mathrm{I} \mathrm{I})$. Duration of follow-up modified the soy-breast cancer association, the effect being twice as large among women with $10+$ vs fewer years of follow-up. Neither oestrogen nor progesterone receptor status of the tumours materially influenced the association. These prospective findings suggest that approximately $10 \mathrm{mg}$ of isoflavones per day, obtained in a standard serving of tofu, may have lasting beneficial effects against breast cancer development.

British Journal of Cancer (2008) 99, 196-200. doi:I0.1038/sj.bjc.6604448 www.bjcancer.com

Published online I July 2008

(c) 2008 Cancer Research UK

Keywords: soy; menopausal status; body size; hormone receptor; breast cancer; Chinese

Of at least 28 detailed studies of soy and breast cancer risk published in English since 1990, 14 were in western populations with very low intake of soy ( $<1 \mathrm{mg}$ of isoflavone per day) and in these, intake was unrelated to breast cancer risk ( $\mathrm{Wu}$ et al, 2008). Of the other 14 studies in Asia or in Asian-Americans with substantially higher soy intake, eight (Lee et al, 1991; Dai et al, 2001; Yamamoto et al, 2003; Hirose et al, 2005; Lee et al, 2005; Shannon et al, 2005; Do et al, 2007) covered the main sources of soy intake and carefully adjusted for relevant potential confounders. In a meta-analysis of these eight studies, we found a stepwise reduction in breast cancer risk with increasing soy intake. Compared to the lowest soy intake $(<5 \mathrm{mg}$ isoflavones per day), risk of breast cancer reduced significantly by $12 \%$ in association with moderate intake ( $\sim 10 \mathrm{mg}$ isoflavones per day) and $29 \%$ in association with high intake (20 isoflavones or more per day; $\mathrm{Wu}$

*Correspondence: $\mathrm{Dr} \mathrm{AH}$ Wu, Department of Preventive Medicine, University of Southern California, 144I Eastlake Ave, Los Angeles, CA 90089, USA; E-mail: annawu@usc.edu

Revised I4 April 2008; accepted 9 May 2008; published online I July 2008 et al, 2008). However, only one Asian study was of cohort type (Yamamoto et al, 2003). Assessment of soy intake was incomplete in two other cohort studies (Key et al, 1999; Nishio et al, 2007) and they were not included in our meta-analysis. Since the publication of our review on soy and breast cancer, no association with soy intake was found in a British cohort with moderate soy intake (Travis et al, 2008). Thus, additional cohort studies of soy and breast cancer risk are needed in populations with substantial soy intake.

We have, therefore, investigated soy intake and breast cancer risk in the Singapore Chinese Health Study (SCHS), a cohort study of diet and cancer.

\section{MATERIALS AND METHODS}

The SCHS was a prospective investigation of the role of dietary factors in cancer aetiology (Hankin et al, 2001). Briefly, 35303 Chinese women and 27954 Chinese men aged 45-74 years of Hokkien or Cantonese dialect group were enrolled in the population-based cohort study between April 1993 and December 1998. At recruitment, information on lifestyle factors, usual diet, and reproductive history (for women only) was obtained through 
in-person interviews. The food frequency questionnaire (FFQ) covered usual intake during the previous 12 months of 165 items identified in a prior 24-h recall study to represent the major food and beverage items in this population. Frequency of consumption was assessed using eight categories for foods and nine categories for beverages, ranging from 'never or hardly ever' to 'two or more times per day.' Colour photographs of portion sizes (small, medium, and large) were used to aid with recall of amounts consumed. A food composition table was developed, and items on the questionnaire were linked to the food composition database.

There are seven common soy products in the Singapore Chinese diet and all are nonfermented. We expressed total soy intake in terms of grams of soy protein, soy isoflavones, and equivalent amounts of tofu per day (Wu et al, 2002). Soy protein intake was calculated using the Singapore Food Composition Table (Hankin et al, 2001). Total soy isoflavone intake was estimated from the summation of the genistein, daidzein, and glycitein contents that have previously been measured in market samples of common soy foods in Singapore. Equivalent amounts of tofu per day were calculated to facilitate comparison with a known dietary item while taking into account the varying water contents across the seven soy foods. This was carried out as follows: the water content of the various soy-containing foods varies from $54 \%$ for cooked foojook, $58 \%$ for cooked foopei, $69 \%$ for cooked taukwa, and $89 \%$ for cooked plain tofu to $92 \%$ for soybean drink. We, therefore, determined that $1 \mathrm{~g}$ of cooked foojook is equivalent to $4.2 \mathrm{~g}(46 / 11)$ of plain tofu, $1 \mathbf{g}$ of cooked foopei is equivalent to $3.8 \mathbf{g}(42 / 11)$ plain tofu, and so on. The total soy intake for each subject was estimated as the summation of all soy foods expressed in units of plain tofu equivalent. In a dietary validation study of SCHS subjects, we found correlation coefficients of $0.63,0.39$, and 0.32 between the FFQ and a series of 24-h recalls for tofu, isoflavone, and soy protein, respectively. Furthermore, dietary intake of soy was statistically significantly correlated with urinary isoflavonoid (Seow et al, 1998).

The SCHS has been continuously followed, both actively through re-interviews and passively through computer linkage to population-based death and cancer registries in Singapore (Seow et $a l, 1996)$. The nationwide cancer registry has been in place since 1968 and is complete in its recording of cancer (Parkin et al, 2002). Loss to follow-up in the cohort has been negligible.

As of 31 December 2005, 629 women had developed breast cancer among the 34028 participants following an accumulation of 338242 person-years (1275 of the 35303 women with prevalent cancer at baseline were excluded). Histological, staging information, oestrogen receptor (ER), and progesterone receptor (PR) status on all breast cancer diagnoses were confirmed by manual review of the pathology reports and clinical charts.

\section{Statistical analysis}

Data were analysed using standard methods for cohort studies. We calculated person-years from the baseline questionnaire to the date of breast cancer diagnosis, death or December 31, 2005, whichever was sooner. Proportional hazards regression methods were used to examine the association between quartiles of isoflavone intake and breast cancer risk, measured by relative risks (RR) and their corresponding 95 percent confidence intervals (95\% CI) in all subjects and among those postmenopausal at baseline. Relevant demographic factors including age (years) at recruitment, year of recruitment (1993-1998), dialect group (Cantonese, Hokkien), education (no formal education, primary school, secondary school, or higher), and established risk factors including age when period became regular $(<12,13-14,15-16$, and $17+$ years or period never became regular), number of live births (none, $1-2,3-4$, and $5+)$, body mass index (BMI; continuous, $\mathrm{kg} \mathrm{m}^{-2}$ ), menopausal status, and n-3 fatty acid intake were adjusted in the analysis. As adjusting for green tea intake, tobacco smoking (never and ever), alcohol intake (nondrinker, monthly, weekly, and daily), and history of diabetes left the results unchanged; we show results without these further adjustments. We conducted subgroup analyses of soy isoflavone intake and risk, stratified by menopausal status and examined the potential effect modification by including interaction terms for body size. We also investigated the effect of soy isoflavone intake by ER and PR status (positive, negative, and unknown), and ER/PR status combined (positive/positive, negative/negative, and unknown/unknown). $P$-value less than $5 \%$ are considered statistically significant and all $P$-values quoted are twosided.

\section{RESULTS}

The mean age of breast cancer patients at diagnosis was 62.0 years (standard deviation (s.d.) 8.2 years; range: $46-86$ years). The mean interval between interview and diagnosis was 5.6 years (range: 1 month - 12 years). Table 1 shows the association between intake of soy isoflavone and risk. Risk was significantly reduced (adjusted $\mathrm{RR}=0.82,95 \% \mathrm{CI}=0.70-0.97 ; P=0.019)$ among women with above median soy intake $\left(>10.6 \mathrm{mg} 1000 \mathrm{Kcal}^{-1}\right)$ compared to those with lower intake $\left(<=10.6 \mathrm{mg} 1000 \mathrm{Kcal}^{-1}\right)$. Results were unchanged after adjustment for intake of green tea, tobacco smoking, alcohol intake, and history of diabetes (data not shown). Table 1 also shows the associations stratified by menopausal status at enrollment. Soy intake was unrelated to risk in premenopausal women $(\mathrm{RR}=1.04, \quad P=0.82)$, but was significantly inversely associated with risk in postmenopausal women with an adjusted $\mathrm{RR}$ for those above the median of $0.74(95 \% \mathrm{CI}=0.61-0.90 ; P$ for interaction $=0.078$ ).

The inverse association between soy intake and breast cancer was statistically significant in postmenopausal women with higher (above median value for all women in the cohort) BMI (adjusted $\mathrm{RR}=0.67,95 \% \mathrm{CI}=0.51-0.88)$ but not in those below the median BMI value (adjusted $\mathrm{RR}=0.83,95 \% \mathrm{CI}=0.62-1.11$ ) (Table 2 ). The two sets of RRs were not statistically different from each other $(P$ for interaction $=0.29)$. Table 3 shows that there were no material differences in the relationship with soy by hormone receptor status in postmenopausal women.

The protective effect of high soy intake was very clear and statistically significant among women with 10 or more years of follow-up $(\mathrm{RR}=0.48,95 \% \mathrm{CI}=0.29-0.78)$ (Table 4$)$. High soy intake was less strongly associated with risk reduction among

Table I Intake of soy isoflavones and breast cancer risk

\begin{tabular}{|c|c|c|c|c|}
\hline $\begin{array}{l}\text { Soy isoflavone } \\
\left(\mathrm{mg} \mathrm{l} 1000 \mathrm{kcal}^{-1}\right)\end{array}$ & $\begin{array}{l}\text { Number of } \\
\text { cases }\end{array}$ & Person-years & $\mathbf{R R}^{\mathbf{a}}$ & $95 \% \mathrm{Cl}$ \\
\hline \multicolumn{5}{|l|}{ All subjects } \\
\hline$<10.6 \mathrm{mg}$ & 339 & 167312 & 1.00 & \\
\hline$\geqslant 10.6 \mathrm{mg}$ & 290 & 170930 & 0.82 & $0.70-0.97$ \\
\hline$P$-value & & & & 0.019 \\
\hline \multicolumn{5}{|c|}{ Menopausal status at baseline } \\
\hline \multicolumn{5}{|l|}{ Premenopausal } \\
\hline$<10.6 \mathrm{mg}$ & 84 & 43668 & 1.00 & \\
\hline$\geqslant 10.6 \mathrm{mg}$ & 106 & 52937 & 1.04 & $0.77-1.40$ \\
\hline$P$-value & & & & 0.82 \\
\hline \multicolumn{5}{|l|}{ Postmenopausal } \\
\hline$<10.6 \mathrm{mg}$ & 255 & 123608 & 1.00 & \\
\hline$\geqslant 10.6 \mathrm{mg}$ & 184 & 117960 & 0.74 & $0.61-0.90$ \\
\hline$P$-value & & & & 0.003 \\
\hline$P$ interaction & & & & 0.08 \\
\hline
\end{tabular}

adjusted for age, years of interview, dialect, education, family history of breast cancer, parity, age when period became regular, menopausal status (if applicable), body mass index, and $n-3$ fatty acid. 
women with less than 10 years of follow-up $(R R=0.88,95 \%$ $\mathrm{CI}=0.74-1.05)$. Results were similar when we restricted the analysis to postmenopausal women (Table 4).

\section{DISCUSSION}

This study found a significant $18 \%$ reduction in breast cancer risk in association with the above median soy isoflavone intake $(\geqslant 10.6 \mathrm{mg}$ $1000 \mathrm{Kcal}^{-1}$ ), a degree of risk reduction compatible with the results that we found in a combined analysis of eight studies in Asian populations with soy intake (Wu et al, 2008). The amount of soy isoflavones ( $\sim 10 \mathrm{mg}$ per day) implicated to have benefit in cancer prevention can be obtained in one standard serving of tofu (Trock et al, 2006). The inverse association with soy intake in this Singapore cohort was statistically significant in postmenopausal but not in premenopausal women (Table 1), but we were limited in studying such women by the lower age limit of this cohort study being 45 years, and only $26 \%$ of participants were aged 45-50 years at enrollment. There is a suggestion that heavier postmenopausal women showed a stronger association than leaner women, although the two sets of RRs are not statistically different from each other (Table 2). The risk reduction with soy intake was found in both ER + and ER - tumours as well as in $\mathrm{PR}+$ and $\mathrm{PR}-$ tumours (Table 3). A stronger soy-breast cancer association was found among women with longer $(10+$ years) duration of follow-up (Table 4).

Table 2 Intake of soy isoflavones and breast cancer risk in postmenopausal women by body mass index

\begin{tabular}{|c|c|c|c|c|}
\hline $\begin{array}{l}\text { Soy isoflavone } \\
\text { (mg/l } 000 \text { kcal) }\end{array}$ & $\begin{array}{l}\text { Number } \\
\text { of cases }\end{array}$ & Person-years & $\mathbf{R R}^{\mathbf{a}}$ & $95 \% \mathrm{Cl}$ \\
\hline \multicolumn{5}{|c|}{ BMI below median $\left(\leqslant 24 \mathrm{~kg} \mathrm{~m}^{-2}\right)$} \\
\hline$<10.6 \mathrm{mg}$ & 110 & 59587 & 1.00 & \\
\hline$\geqslant 10.6 \mathrm{mg}$ & 90 & 57772 & 0.83 & $0.62-1.11$ \\
\hline$P$-value & & & & 0.21 \\
\hline \multicolumn{5}{|c|}{ BMl above median (> $24 \mathrm{~kg} \mathrm{~m}^{-2}$ ) } \\
\hline$<10.6 \mathrm{mg}$ & 145 & 64021 & 1.00 & \\
\hline$\geqslant 10.6 \mathrm{mg}$ & 94 & 60187 & 0.67 & $0.51-0.88$ \\
\hline$P$-value & & & & 0.004 \\
\hline$P$ interaction & & & & 0.29 \\
\hline
\end{tabular}

${ }^{a}$ Adjusted for age, years of interview, dialect, education, family history of breast cancer, parity, age when period became regular, body mass index, and n-3 fatty acid.
To date, eight cohort/nested case-control studies have investigated the association between soy intake and breast cancer risk, of which four were not very informative, being conducted in western populations with very low soy intake (average of $\sim 1 \mathrm{mg}$ of soy isoflavones per day). Of these, no association was found in three studies in populations with very low soy intake (Horn-Ross et al, 2002; Keinan-Boker et al, 2004; Touillaud et al, 2006), whereas one study found an increased risk (Grace et al, 2004).

The other four cohort studies were in populations with moderate-to-high soy intake, one in the Oxford arm of the European Prospective Investigation into Cancer and Nutrition (EPIC-Oxford), one of the few non-Asian populations with moderate soy intake. The mean daily soy isoflavone intake was $2.9 \mathrm{mg}$ among non-vegetarians and $10.2 \mathrm{mg}$ among vegetarians, but only about $30 \%$ of the 37643 cohort participants were vegetarians, limiting the investigation of this question (Travis et al, 2008). Three studies were conducted in Japan (Key et al, 1999; Yamamoto et al, 2003; Nishio et al, 2007) with high soy intake. Our finding of a significant inverse association between soy intake and breast cancer, particularly in postmenopausal women is similar to that reported in the Japan Public Health Center-Based Prospective Study (JPHC) (Yamamoto et al, 2003). Soy intake in the JPHC study was obtained using a validated FFQ including intake of five soy foods, covering approximately $90 \%$ of the total soy isoflavone intake in Japan (Yamamoto et al, 2001). In contrast, breast cancer risk was unrelated to soy intake in two other Japanese cohort studies (Key et al, 1999; Nishio et al, 2007); assessment of soy intake was less complete in both studies and considerable random misclassification of soy exposure is likely to have led to underestimation of risk (ie, bias towards the null).

After the menopause, adipose tissue is the major site for oestrogen synthesis and high body size is associated with the elevated endogenous oestrogen (Judd et al, 1982). We noted a stronger association among postmenopausal women with below $v s$ above median BMI, although the two sets of RRs were not statistically different from each other. In a case-control study among women in Shanghai, China, the inverse association was more evident in women with higher BMI $\left(25+\mathrm{kg} \mathrm{m}^{-2}\right)$ than women with lower BMI irrespective of menopausal status (Dai et al, 2001). In the four cohort studies reviewed in the previous paragraph, the soy-breast cancer association was not examined separately by BMI category.

Our results show comparable effects of soy on ER + and ERtumours as well as PR + and PR - tumours (Table 3). Of the eight studies included in our meta-analysis on soy and breast cancer in

Table 3 Intake of soy isoflavones and breast cancer risk $(\mathrm{RR}, 95 \% \mathrm{Cl})^{\mathrm{a}}$ in postmenopausal women by oestrogen receptor (ER) and progesterone receptor (PR) status

\begin{tabular}{|c|c|c|c|c|c|c|c|}
\hline \multirow[t]{2}{*}{$\begin{array}{l}\text { Soy isoflavone } \\
\left(\mathrm{mg} \mathrm{l} 000 \mathrm{kcal}^{-1}\right)\end{array}$} & \multirow[t]{2}{*}{ Person-years } & \multicolumn{2}{|c|}{$\begin{array}{l}\text { Hormone receptor } \\
\text { (positive) }\end{array}$} & \multicolumn{2}{|c|}{$\begin{array}{c}\text { Hormone receptor } \\
\text { (negative) }\end{array}$} & \multicolumn{2}{|c|}{$\begin{array}{l}\text { Hormone receptor } \\
\text { (unknown) }\end{array}$} \\
\hline & & $N$ & $\mathrm{ER}+$ & $N$ & ER- & $N$ & ER DK \\
\hline$<10.6 \mathrm{mg}$ & 122868 & || $\mid$ & 1.00 & 56 & 1.00 & 88 & 1.00 \\
\hline$\geqslant 10.6 \mathrm{mg}$ & | | 7370 & 73 & $0.67(0.49-0.91)$ & 36 & $0.66(0.42-1.02)$ & 75 & $0.89(0.64-1.22)$ \\
\hline$P$-value & & & 0.01 & & 0.06 & & 0.46 \\
\hline & & $N$ & $\mathrm{PR}+$ & $N$ & PR- & $N$ & PR DK \\
\hline$<10.6 \mathrm{mg}$ & 122667 & 77 & 1.00 & 87 & 1.00 & 91 & 1.00 \\
\hline$\geqslant 10.6 \mathrm{mg}$ & 117264 & 53 & $0.69(0.48-1.00)$ & 56 & $0.67(0.47-0.95)$ & 75 & $0.85(0.62-1.17)$ \\
\hline$P$-value & & & 0.047 & & 0.02 & & 0.32 \\
\hline & & N & $\mathrm{ER}+\mathrm{PR}+$ & $N$ & ER-PR- & $N$ & $E R \& P R D^{b}$ \\
\hline$<10.6 \mathrm{mg}$ & $|2265|$ & 74 & 1.00 & 51 & 1.00 & 88 & 1.00 \\
\hline$\geqslant 10.6 \mathrm{mg}$ & 117262 & 52 & $0.70(0.48-1.01)$ & 35 & $0.70(0.45-1.10)$ & 75 & $0.89(0.64-1.22)$ \\
\hline$P$-value & & & 0.060 & & 0.12 & & 0.46 \\
\hline
\end{tabular}

${ }^{a}$ Adjusted for age, years of interview, dialect, education, family history of breast cancer, parity, age when period became regular, body mass index, and $\mathrm{n}-3$ fatty acid. ${ }^{b}$ We did not include breast cancers that were $\mathrm{ER}+\mathrm{PR}-(n=57)$, ER+PR unknown $(n=1)$, ER-PR+ $(n=4)$ or ER-PR unknown $(n=2)$ in the analysis. 
Table 4 Intake of soy isoflavones and breast cancer risk by the length of follow-up

\begin{tabular}{|c|c|c|c|c|c|}
\hline $\begin{array}{l}\text { Follow-up } \\
\text { (years) }\end{array}$ & $\begin{array}{l}\text { Soy isoflavone } \\
\left(\mathrm{mg} \mathrm{l} 1000 \mathrm{kcal}^{-1}\right)\end{array}$ & $\begin{array}{l}\text { All subjects (number } \\
\text { of cases/person-years) }\end{array}$ & $\mathbf{R R}^{\mathrm{a}}(95 \% \mathrm{Cl})$ & $\begin{array}{c}\text { Postmenopausal } \\
\text { (number of cases/person-years) }\end{array}$ & $\operatorname{RR}^{\mathrm{a}}(95 \% \mathrm{Cl})$ \\
\hline \multicolumn{6}{|l|}{$0-<10$ years } \\
\hline \multicolumn{6}{|l|}{$10+$ years } \\
\hline
\end{tabular}

${ }^{a}$ Adjusted for age, years of interview, dialect, education, family history of breast cancer, parity, age when period became regular, menopausal status (if applicable), body mass index, and n-3 fatty acid.

Asian populations (Wu et al, 2008), only one study in our metaanalysis investigated the risk by hormone receptor status, finding the effect more apparent for tumours that were positive for both ER and PR (Dai et al (2001). Further investigation of the soybreast cancer association by menopausal status and ER/PR status will be needed.

Three studies (Shu et al, 2001; Wu et al, 2002; Thanos et al, 2006), including a case-control study that we conducted among Asian American women in Los Angeles County, found that the timing of soy exposure is an important codeterminant of risk, with stronger effects from exposures at earlier ages. This study lends further support to soy exposures occurring during the earlier stages of carcinogenesis and would result in a greater degree of reduction in a woman's subsequent risk for breast cancer. We noted that the magnitude of risk reduction among women with 10 or more years between exposure assessment and cancer diagnosis was twice than that among their counterparts with shorter time intervals. Interestingly, this model may explain the seemingly contradictory findings from recent soy intervention studies with generally null findings (Maskarinec et al, 2004; Wu et al, 2005).

This prospective study has several important strengths. First, information on soy intake and other risk factors was obtained inperson before cancer diagnosis and thus the recall bias is not a concern. This is particularly important as seven of the eight studies in our meta-analysis on soy and breast cancer were case-control studies (Wu et al, 2008). Second, we used a validated FFQ, our assessment of soy intake was relatively complete, and dietary intake of soy was statistically significantly correlated with urine isoflavone levels (Seow et al, 1998). Third, our study is larger than previous cohort studies on this topic (two of the previous studies had less than 200 breast cancer cases (Yamamoto et al, 2003; Nishio et al, 2007). The larger sample size, particularly of postmenopausal women, has allowed us to investigate the potential modifying effect of body size on the soy-breast cancer association in postmenopausal women. Finally, we were able to examine the risk pattern by hormone receptor status, apparently the first such from a prospective study.

In summary, among 34028 women in the SCHS, high soy intake $(\geqslant 10.6 \mathrm{mg}$ isoflavones per $1000 \mathrm{Kcal})$ was associated with a significant $18 \%$ reduction in breast cancer risk. Our results adds to the compelling results obtained from case-control studies on soy and breast cancer and suggest that the soy isoflavones may have lasting beneficial effects against breast cancer development. The level of soy isoflavones implicated to have benefit $(\sim 10 \mathrm{mg}$ isoflavones per day or one standard serving of tofu) is achievable even in populations that do not typically eat soy foods.

\section{ACKNOWLEDGEMENTS}

This study was supported by Grants R01CA102065, R01CA55069, R35CA53890, and R01CA80205 from the National Cancer Institute. We thank Low Siew-Hong of the National University of Singapore for supervising the fieldwork of the Singapore Chinese Health Study. We also thank the Ministry of Health in Singapore for the assistance with the identification of cancer cases through database linkages. None of the authors have any conflicts of interest.

\section{REFERENCES}

Dai Q, Shu XO, Jin F, Potter JD, Kushi LH, Teas J, Gao YT, Zheng W (2001) Population-based case-control study of soyfood intake and breast cancer risk in Shanghai. Br J Cancer 85: $372-378$

Do MH, Lee SS, Jung PJ, Lee MH (2007) Intake of fruits, vegetables, and soy foods in relation to breast cancer risk in Korean women: a case - control study. Nutr Cancer 57: 20-27

Grace PB, Taylor JI, Low YL, Luben RN, Mulligan AA, Botting NP, Dowsett M, Welch AA, Khaw KT, Wareham NJ, Day NE, Bingham SA (2004) Phytoestrogen concentrations in serum and spot urine as biomarkers for dietary phytoestrogen intake and their relation to breast cancer risk in European prospective investigation of cancer and nutrition-norfolk. Cancer Epidemiol Biomarkers Prev 13: $698-708$

Hankin JH, Stram DO, Arakawa K, Park S, Low SH, Lee HP, Yu MC (2001) Singapore Chinese Health Study: development, validation, and calibration of the quantitative food frequency questionnaire. Nutr Cancer 39: $187-195$

Hirose K, Imaeda N, Tokudome Y, Goto C, Wakai K, Matsuo K, Ito H, Toyama T, Iwata H, Tokudome S, Tajima K (2005) Soybean products and reduction of breast cancer risk: a case-control study in Japan. Br J Cancer 93: 15-22

Horn-Ross PL, Hoggatt KJ, West DW, Krone MR, Stewart SL, Anton H, Bernstei CL, Deapen D, Peel D, Pinder R, Reynolds P, Ross RK, Wright W, Ziogas A (2002) Recent diet and breast cancer risk: the California Teachers Study (USA). Cancer Causes Control 13: 407-415

Judd HL, Shamonki IM, Frumar AM, Lagasse LD (1982) Origin of serum estradiol in postmenopausal women. Obstet Gynecol 59: 680-686

Keinan-Boker L, van Der Schouw YT, Grobbee DE, Peeters PH (2004) Dietary phytoestrogens and breast cancer risk. Am J Clin Nutr 79: 282-288

Key TJ, Sharp GB, Appleby PN, Beral V, Goodman MT, Soda M, Mabuchi K (1999) Soya foods and breast cancer risk: a prospective study in Hiroshima and Nagasaki, Japan. Br J Cancer 81: $1248-1256$

Lee HP, Gourley L, Duffy SW, Esteve J, Lee J, Day NE (1991) Dietary effects on breast cancer risk in Singapore. Lancet 337: 1197-1200 
Lee MM, Chang IY, Horng CF, Chang JS, Cheng SH, Huang A (2005) Breast cancer and dietary factors in Taiwanese women. Cancer Causes Control 16: $929-937$

Maskarinec G, Takata Y, Franke AA, Williams AE, Murphy SP (2004) A 2-year soy intervention in premenopausal women does not change mammographic densities. J Nutr 134: 3089-3094

Nishio K, Niwa Y, Toyoshima H, Tamakoshi K, Kondo T, Yatsuya H, Yamamoto A, Suzuki S, Tokudome S, Lin Y, Wakai K, Hamajima N, Tamakoshi A (2007) Consumption of soy foods and the risk of breast cancer: findings from the Japan Collaborative Cohort (JACC) Study. Cancer Causes Control 18: $801-808$

Parkin DM, Ww S, Ferlay J, Teppo L, Thomas D (2002) Cancer Incidence in Five Continents. Lyon: IARC

Seow A, Duffy SW, McGee MA, Lee J, Lee HP (1996) Breast cancer in Singapore: trends in incidence 1968-1992. Int J Epidemiol 25: 40-45

Seow A, Shi CY, Franke AA, Hankin JH, Lee HP, Yu MC (1998) Isoflavonoid levels in spot urine are associated with frequency of dietary soy intake in a population-based sample of middle-aged and older Chinese in Singapore. Cancer Epidemiol Biomarkers Prev 7: 135-140

Shannon J, Ray R, Wu C, Nelson Z, Gao DL, Li W, Hu W, Lampe J, Horner N, Satia J, Patterson R, Fitzgibbons D, Porter P, Thomas D (2005) Food and botanical groupings and risk of breast cancer: a case-control study in Shanghai, China. Cancer Epidemiol Biomarkers Prev 14: 81-90

Shu XO, Jin F, Dai Q, Wen W, Potter JD, Kushi LH, Ruan Z, Gao YT, Zheng W (2001) Soyfood intake during adolescence and subsequent risk of breast cancer among Chinese women. Cancer Epidemiol Biomarkers Prev 10: 483 - 488

Thanos J, Cotterchio M, Boucher BA, Kreiger N, Thompson LU (2006) Adolescent dietary phytoestrogen intake and breast cancer risk (Canada). Cancer Causes Control 17: 1253-1261
Touillaud MS, Thiebaut AC, Niravong M, Boutron-Ruault MC, ClavelChapelon F (2006) No association between dietary phytoestrogens and risk of premenopausal breast cancer in a French cohort study. Cancer Epidemiol Biomarkers Prev 15: 2574-2576

Travis RC, Allen NE, Appleby PN, Spencer EA, Roddam AW, Key T] (2008) A prospective study of vegetarianism and isoflavone intake in relation to breast cancer risk in British women. Int J Cancer 122: $705-710$

Trock BJ, Hilakivi-Clarke L, Clarke R (2006) Meta-analysis of soy intake and breast cancer risk. J Natl Cancer Inst 98: 459-471

Wu AH, Stanczyk FZ, Martinez C, Tseng CC, Hendrich S, Murphy P, Chaikittisilpa S, Stram DO, Pike MC (2005) A controlled 2-mo dietary fat reduction and soy food supplementation study in postmenopausal women. Am J Clin Nutr 81: 1133-1141

Wu AH, Stanczyk FZ, Seow A, Lee HP, Yu MC (2002) Soy intake and other lifestyle determinants of serum estrogen levels among postmenopausal Chinese women in Singapore. Cancer Epidemiol Biomarkers Prev 11: $844-851$

Wu AH, Yu MC, Tseng CC, Pike MC (2008) Epidemiology of soy exposures and breast cancer risk. Br J Cancer 98: 9-14

Yamamoto S, Sobue T, Kobayashi M, Sasaki S, Tsugane S (2003) Soy, isoflavones, and breast cancer risk in Japan. J Natl Cancer Inst 95: 906-913

Yamamoto S, Sobue T, Sasaki S, Kobayashi M, Arai Y, Uehara M, Adlercreutz H, Watanabe S, Takahashi T, Iitoi Y, Iwase Y, Akabane M, Tsugane S (2001) Validity and reproducibility of a self-administered food-frequency questionnaire to assess isoflavone intake in a japanese population in comparison with dietary records and blood and urine isoflavones. J Nutr 131: $2741-2747$ 